CONTIPELLI, Ernani. Policentrismo, governança climática e constitucionalismo global. Revista Eletrônica Direito e Política, Programa de Pós-Graduação Stricto Sensu em Ciência Jurídica da UNIVALI, Itajaí, v.14, n.1, $1^{\circ}$ quadrimestre de 2019. Disponível em: www.univali.br/direitoepolitica - ISSN 1980-7791

\title{
POLICENTRISMO, GOVERNANÇA CLIMÁTICA E CONSTITUCIONALISMO GLOBAL
}

\author{
POLYCENTRISM, CLIMATE GOVERNANCE \\ AND GLOBAL CONSTITUTIONALISM
}

Ernani Contipelli ${ }^{1}$

\begin{abstract}
RESUMO
A abordagem alternativa e pluralística desempenhada pelo policentrismo tem por finalidade maximizar a convergência de múltiplas unidades de governança, presentando-se como um fator de estimulo à realização de ações coletivas e coordenadas em diferentes escalas de poder, ao resgatar os índices de confiança e cooperação entre cidadãos e comunidades, especialmente, para enfrentar ameaças globais, como o caso da atual crise climática, a qual tem sido objeto de falhas institucionais, em razão de equivocadas estratégias implementadas no plano internacional. O presente estudo pretende discutir a aplicação do policentrismo no âmbito da governança climática multinível, destacando a importância de fatores que promovam um esquema compreensivo de princípios e regras através de modelos institucionais determinados a partir da utilização da teoria do constitucionalismo global, com a função de orientar a coordenação de iniciativas entre diversos níveis de autoridade, para valorizar processos de conhecimento e aprendizado que influenciem a performance de todo sistema climático global.
\end{abstract}

PALAVRAS-CHAVE: Policentrismo; Governança Climática; Constitucionalismo Global.

\section{ABSTRACT}

The alternative and pluralistic approach of the polycentrism aims to maximize the convergence of multiple governance units, presenting itself as a stimulate factor to the performance of collective and coordinate actions in different scales of power in order to rescue the levels of trust and cooperation between citizens and communities, specially, in order to confront global threats, as the case of the climate crisis, which had institutional fails in addressing international strategies. The present study propose a discussion about the application of the polycentrism in the framework of the multilevel climate governance, highlighting the relevance of factors that promote a comprehensive scheme of principles and rules through certain institutional models determined by the theory of the global constitutionalism which aims to guide initiatives in different levels of authorities

\footnotetext{
${ }^{1}$ Professor do Programa de Mestrado em Direito, Universidade Comunitária da Região de Chapecó (UNOCHAPECO); ernanicontipelli@gmail.com
} 
CONTIPELLI, Ernani. Policentrismo, governança climática e constitucionalismo global. Revista Eletrônica Direito e Política, Programa de Pós-Graduação Stricto Sensu em Ciência Jurídica da UNIVALI, Itajaí, v.14, n.1, $1^{\circ}$ quadrimestre de 2019. Disponível em: www.univali.br/direitoepolitica - ISSN 1980-7791

in order to emphasize the knowledge and learning processes that effects the whole global climate system.

KEYWORDS: Polycentrism; Climate Governance; Global Constitutionalism.

\section{INTRODUÇÃO}

Para enfrentar e compreender as questões relativas aos desafios globais, como o caso da mudança climática, os quais atuam em diferentes níveis de interação que envolvem o ser humano e o meio ambiente, verifica-se a necessidade de utilização de métodos alternativos e pluralísticos para investigação de modelos de governança que busquem encorajar a multiplicação de ações através de um processo de experimentação desenvolvido em uma variedade de quadros e condutas sociais.

Em tal contexto, o policentrismo pode ser compreendido como uma proposta de analise de mecanismos de governança que pretende valorizar a realização de ações coletivas e complexas em múltiplas esferas de poder como forma de melhor apreender e confrontar a atual crise climática, constatando os processos que asseguram e mantem índices adequados de confiança e de cooperação mutua entre distintas instituições e atores interessados.

Assim, o presente artigo apresenta o policentrismo como uma perspectiva de investigação de modelos de governança, que contribui para produção de abertura de espaços políticos orientados à experimentação e inovação, enfatizando a importância de ações coletivas que devem atuar no incremento dos níveis de solidariedade e de reciprocidade social, os quais foram profundamente atingidos pelo evidente insucesso das negociações realizadas no âmbito internacional para enfrentar a mudança climática. Nesse contexto, ingressa-se também na discussão sobre os elementos de coordenação das mencionadas ações coletivas propostas pelo policentrismo, a partir da aplicação da teoria do constitucionalismo global. 
CONTIPELLI, Ernani. Policentrismo, governança climática e constitucionalismo global. Revista Eletrônica Direito e Política, Programa de Pós-Graduação Stricto Sensu em Ciência Jurídica da UNIVALI, Itajaí, v.14, n.1, $1^{\circ}$ quadrimestre de 2019. Disponível em: www.univali.br/direitoepolitica - ISSN 1980-7791

\section{CONCEITO DE POLICENTRISMO}

Inicialmente, deve-se compreender que a perspectiva de analise de sistemas caracterizados pelo policentrismo enfatizam a presença de múltiplas autoridades em diferentes níveis de governo, em que as respectivas unidades funcionam através de jurisdições sobrepostas, operando com uma ampla margem de autonomia e implementando normas e regras dentro de um domínio especifico (como família, empresa, governo local, ou mesmo através de jurisdições estatais, regionais, nacionais ou internacionais) ${ }^{2}$.

Tal ideia é consagrada desde a introdução do conceito de policentrismo, apresentado em 1961 no emblemático artigo escrito por Vincent Ostrom, Charles Tiebout e Robert Warren, denominado "A Organização do Governo nas Áreas Metropolitanas: Um Inquirição Teórica", o qual destaca a existência de um sistema composto por diversas unidades autônomas e formalmente independentes uma das outras, que optam por agir através do processo de cooperação, competição e resolução de conflitos $^{3}$.

O policentrismo pode ser definido, então, como o gerenciamento de atividades sociais dentro de múltiplas unidades inter-relacionadas, as quais devem ser, inicialmente, determinadas como centros individuais, para organizar suas ações e relacionamentos com as demais unidades em favor do alcance de um objetivo comum. No artigo anteriormente mencionado, foram tomadas como exemplo as áreas metropolitanas dos Estados Unidos, que, sob determinadas condições, poderiam aplicar métodos de gestão comunitária, que aprimorariam o padrão até então predominante, fundado em estruturas centralizadas ${ }^{4}$.

\footnotetext{
2 Elinor Ostrom. Polycentric Systems for Coping with Collective Action and Global Environmental Change, Global Environmental Change 20, 550-557 (2010), p. 552.

3 Vicent Ostrom, Charles M. Tiebout and Robert Warren. The Organization of Government in Metropolitan Areas: A Theoretical Inquiry. American Political Science Review 55 (4), 831-842 (1961).

${ }^{4}$ Marcel J. Dorsch and Christian Flatchsland. A Polycentric Approach to Global Climate Governance. Global Environmental Politics, Vol. 17, Number 2, 45-64 (2017), p. 48.
} 
CONTIPELLI, Ernani. Policentrismo, governança climática e constitucionalismo global. Revista Eletrônica Direito e Política, Programa de Pós-Graduação Stricto Sensu em Ciência Jurídica da UNIVALI, Itajaí, v.14, n.1, $1^{\circ}$ quadrimestre de 2019. Disponível em: www.univali.br/direitoepolitica - ISSN 1980-7791

Assim, o policentrismo estimula interações entre varias unidades de governança, encorajando a coordenação de ações a partir de uma serie de jurisdições sobrepostas que proporcionem um ambiente de autonomia, reciprocidade e cooperação para realização de trabalhos conjuntos. Nestes termos, Vincent Ostrom afirma que os sistemas policêntricos são aqueles em que muitos elementos são capazes de fazer ajustes mútuos para ordenar seus relacionamentos recíprocos dentro de um quadro geral de regras, onde cada unidade atua com independência em relação às demais 5 .

Em outras palavras, a policentricidade estimula interações benéficas entre múltiplas unidades presentes em um dado sistema de governança, o que inclui a coordenação de suas próprias atividades com uma mentalidade recíproca e cooperativa, propondo uma lógica onde diferenças potenciais são governadas por uma série de regulamentações abrangentes, que geram condições necessárias para convergência de ações em todo os sistema, garantindo sua execução e fornecendo informações para fomentar negociações entre as instituições e os atores envolvidos ${ }^{6}$.

Desde uma perspectiva policêntrica, as ações convergentes de diferentes unidades de poder, especialmente entre comunidades locais (o que inclui sua autonomia para instituições de regras, assim como a capacidade para monitorar e comunicar face-a-face com os cidadãos) ${ }^{7}$ compreendem fatores conclusivos para determinar o sucesso ou falha na governança de interesses públicos, na medida em que tais instituições, a partir de um conjunto compreensivo de regras, possuem o potencial para maximizar a orientação do comportamento social em favor do cumprimento de tarefas mutuas e da resolução adequada de possíveis disputas.

\footnotetext{
5 Vicent Ostrom. Polycentricity - Part I. In Polycentricity and Local Public Economics. Ed. Michel Mc Ginis, 52-74. Ann Arbor: University of Michigan Press (1999).

${ }^{6}$ Benjamin K. Sovacool. An International Comparison of Four Polycentric Approaches to Climate and Energy Governance. Energy Policy, 39, 3832-3844 (2011), p. 3842/3843.

7 James M. Walker, Roy Gardner, Andrew Herr and Elionor Ostrom, Collective Choice in the Commons: Experimental Results on Proposed Allocation Rules and Votes. The Economic Journal, 110, 212-234 (2000), pp. 212/213.
} 
CONTIPELLI, Ernani. Policentrismo, governança climática e constitucionalismo global. Revista Eletrônica Direito e Política, Programa de Pós-Graduação Stricto Sensu em Ciência Jurídica da UNIVALI, Itajaí, v.14, n.1, $1^{\circ}$ quadrimestre de 2019. Disponível em: www.univali.br/direitoepolitica - ISSN 1980-7791

\subsection{Policentrismo e Problemas Globais}

Com a intensificação do processo de globalização, torna-se evidente a existência de problemas comuns em escala mundial, gerando maior incremento das relações de interdependência entre Estados-nações e a necessidade de uma agenda política direcionada à realização de esforços cooperativos para solução dessas questões globais, também chamadas de "problemas sem passaporte", como sugerido pelo antigo secretário-geral da ONU Kofi Annan.

Significa dizer que os problemas globais somente podem ser devidamente gerenciados a partir da superação de fronteiras, problemas que não pertencem a esse ou aquele país, mas todo o mundo, o que revela a necessidade de uma revisão de certos paradigmas, como, por exemplo, a tradicional ideia de soberania, na medida em que a regulação jurídica não esta mais contida exclusivamente nas fronteiras do constitucionalismo e, consequentemente, precisa buscar novas soluções para desempenhar seu papel diante da sociedade.

Elinor Ostrom destaca que quando estamos diante de tais problemas globais, como o caso da mudança climática, eles se relacionam com os resultados cumulativos das ações de indivíduos, famílias, pequenos grupos, empresas privadas, ou mesmo de governos locais, regionais e nacionais, o que demanda um grande esforço na realização de ações coletivas e complexas que incremente os níveis de confiança e de reciprocidade, para promoção de cooperações voluntarias entre os cidadãos ${ }^{9}$.

Problemas globais envolvem um importante fator: tempo, o qual consiste em uma variável que não é facilmente acordada no âmbito internacional e que pode frustrar as chances de identificação de soluções justas para prevenir graves repercussões na sociedade. Ademais, as negociações no plano internacional requerem o apoio de instancias nacionais, regionais e locais para funcionarem efetivamente. Em tal sentido, Elinor Ostrom chama a atenção para o fato de que

\footnotetext{
${ }^{8}$ Ernani Contipelli. Trump's Doctrine and Climate Change: New Challenges for Global Governance. IndraStra Global, v. 3, n. 5, 3-68 (2017), p. 05.

9 Elinor Ostrom. Polycentric Systems for Coping with Collective Action and Global Environmental Change, Global Environmental Change 20, 550-557 (2010), p. 550.
} 
CONTIPELLI, Ernani. Policentrismo, governança climática e constitucionalismo global. Revista Eletrônica Direito e Política, Programa de Pós-Graduação Stricto Sensu em Ciência Jurídica da UNIVALI, Itajaí, v.14, n.1, $1^{\circ}$ quadrimestre de 2019. Disponível em: www.univali.br/direitoepolitica - ISSN 1980-7791

embora a maior parte dos efeitos da mudança climática sejam globais, suas causas possuem origem em planos inferiores (nacionais, regionais e locais) ${ }^{10}$.

Contemporaneamente, o sucesso das instituições de governança global é indiscutivelmente policêntrico, pois nenhum sistema internacional pode alcançar adequadamente suas metas sem o apoio de legislações nacionais, assim como monitorar o cumprimento de sua execução no âmbito nacional e subnacional sem o envolvimento ativo de grupos governamentais e não-governamentais no plano local ${ }^{11}$.

Nessa linha de pensamento, Daniel H. Cole entende que o método policêntrico encontra nos planos institucionais inferiores, especialmente, o local, as melhores ofertas de serviços públicos aos cidadãos e à comunidade, em razão de sua eficácia, pois os atores envolvidos podem selecionar os produtores e os provedores que melhor atendam a cada problema especifico ${ }^{12}$.

Logicamente, a informação, como por exemplo, dados sobre os custos e benefícios imediatos e de longo prazo das ações disponibilizadas, possui um papel relevante em tal contexto para a definição do quadro comportamental humano, sobretudo, para alcançar níveis adequados de confiança e de reciprocidade, desenvolvendo a cooperação sustentável entre indivíduos e grupos através de soluções de "auto-organização" destinadas à gestão de recursos públicos em âmbito local e regional ${ }^{13}$.

A opção por incluir unidades de governança de pequena e de media escala com suas respectivas redes de informação e intensidade de monitoramento de execução de ações coletivas se mostra mais efetivas no tratamento de problemas globais como a mudança climática. Tal circunstancia ocorre porque a

\footnotetext{
10 Elinor Ostrom. A Multi-Scale Approach to Coping with Climate Change and Other Collective Action Problems. Solutions 1 (2): 27-36 (2010), p. 28.

11 Daniel H. Cole. From Global to Polycentric Climate Governance. Climate Law 2, 395-413 (2011), p. 396.

12 Daniel H. Cole. Advantages of a Polycentric Approach to Climate Change Policy. Nature Climate Change, vol. 05, (2015), p. 114.

13 Elinor Ostrom. A Multi-Scale Approach to Coping with Climate Change and Other Collective Action Problems. Solutions 1 (2): 27-36 (2010), p. 30.
} 
CONTIPELLI, Ernani. Policentrismo, governança climática e constitucionalismo global. Revista Eletrônica Direito e Política, Programa de Pós-Graduação Stricto Sensu em Ciência Jurídica da UNIVALI, Itajaí, v.14, n.1, $1^{\circ}$ quadrimestre de 2019. Disponível em: www.univali.br/direitoepolitica - ISSN 1980-7791

perspectiva multinível induz à realização de esforços experimentais em diferentes escalas de interesses, fornecendo uma analise comparativa de descobertas em ambientes específicos, para facilitar a estimativa de custos e de benefícios das estratégias e fortalecer os índices de confiança reciproca no cumprimento de ações cooperativas ${ }^{14}$.

Segundo Elinor Ostrom, quando as medidas de controle dos problemas globais são enfocadas apenas no plano internacional, torna-se mais difícil incrementar os níveis de confiança e de reciprocidade que precisam ser construídos para que cidadãos e instituições realmente acreditem que as medidas que estão sendo implementadas em seu âmbito de vida social também estão sendo cumpridas "na outra metade do mundo". E ela salienta que, quando os envolvidos temem que estão sendo tratados como "otários" por arcarem com os custos das ações, enquanto os demais parecem não se comprometer, um maior esforço deve ser realizado para encontrar maneiras ilusórias para demonstrar a redução de emissões de gases de efeito estufa, embora isso não esteja realmente ocorrendo ${ }^{15}$.

Portanto, a perspectiva policêntrica e sua proposta de governança multinível oferecem um amplo quadro para experimentação, escolha e aprendizado dentro de organizações sociais, impulsionando a inovação, a adaptação, a confiabilidade, o nível de cooperação entre os atores envolvidos e a obtenção de resultados mais vantajosos, equitativos e sustentáveis em diversas escalas de interesses, especialmente, quando se está diante de problemas globais, como a crise climática.

\section{GOVERNANÇA CLIMÁTICA MULTINÍVEL}

É evidente que nenhuma nação foi capaz de minimizar com sucesso suas emissões de gases de efeito estufa. Infelizmente, a Convenção-Quadro das

\footnotetext{
${ }^{14}$ Elinor Ostrom. A Polycentric Approach for Coping with Climate Change. Policy Research Working Paper 5095, World Bank, 2009, p. 11.

15 Elinor Ostrom, supra nota 10, p. 33.
} 
CONTIPELLI, Ernani. Policentrismo, governança climática e constitucionalismo global. Revista Eletrônica Direito e Política, Programa de Pós-Graduação Stricto Sensu em Ciência Jurídica da UNIVALI, Itajaí, v.14, n.1, $1^{\circ}$ quadrimestre de 2019. Disponível em: www.univali.br/direitoepolitica - ISSN 1980-7791

Nações Unidas sobre Mudança Climática (UNFCCC, sigla em inglês) em seu primeiro momento de aplicação juntamente com o Protocolo de Kyoto, falhou, especialmente, ao optar por estratégias que não previam a implementação de ações coordenadas que pudessem promover o engajamento de diferentes níveis de governança e de distintos grupos e indivíduos na luta contra a crise climática.

Daniel H. Cole expressa suas apreensões e ceticismo em relação ao paupérrimo avanço realizado nas negociações climáticas em escala global, ressaltando que depois de mais de 20 anos de reuniões sobre o clima no âmbito das Nações Unidas apenas uma pequena parcela de confiança mutua se desenvolveu até agora. Em realidade, uma revisão dos relatórios das recentes reuniões globais sobre o clima indica altos níveis de desconfiança, representados não apenas pela falta de progresso na mitigação, mas também pela existência de conflitos entre as partes ${ }^{16}$.

Dentro de uma perspectiva policêntrica, em que se pretende investigar as formas como os diferentes níveis de governança estão enfrentando os desafios globais, deve ser identificado, especialmente em termos institucionais, que oportunidades de participação estão sendo geradas aos diversos atores envolvidos nos processos de decisões politicas, com a finalidade de fomentar um ambiente cooperativo de solidariedade e de reciprocidade, para conter a crise climática e controlar o aquecimento global.

Compreender, então, a abordagem policêntrica na dinâmica da governança climática multinível, exige uma atenção especial às particularidades relacionadas aos conceitos de hierarquia e de policentrismo, assim como as maneiras pelas quais eles atuam dentro da estrutura existente entre as inúmeras instituições envolvidas na luta contra a mudança climática.

Primeiramente, é preciso reconhecer que a governança multinível funciona em diferente escalas de governo, através de relações horizontais, verticais e diagonais entre instituições, planos de conexões e respectivas regiões geográficas. Bodansky, Brunnée e Rajamani descreveram tal dinâmica da

16 Daniel H. Cole, supra nota 09, p. 117. 
CONTIPELLI, Ernani. Policentrismo, governança climática e constitucionalismo global. Revista Eletrônica Direito e Política, Programa de Pós-Graduação Stricto Sensu em Ciência Jurídica da UNIVALI, Itajaí, v.14, n.1, $1^{\circ}$ quadrimestre de 2019. Disponível em: www.univali.br/direitoepolitica - ISSN 1980-7791

governança multinivel como relações horizontais existentes entre instituições situadas no mesmo âmbito hierárquico ou geográfico; como relações verticais, aquelas entre instituições situadas em níveis distintos; e como diagonais são as existentes entre instituições em variados níveis situados em diferentes países ${ }^{17}$.

Desta feita, a governança climática multinível tem por finalidade explorar o conteúdo das relações que podem existir entre diferentes e específicos níveis de governança, construindo conexões com iniciativas internacionais, transnacionais, nacionais e subnacionais, e respeitando o quadro de atuação estabelecido pela estrutura do sistema climático global, para garantir a consecução de um objetivo comum: controlar a atual crise climática ${ }^{18}$.

Tais relações são distinguíveis em duas categorias ideais: hierárquica, na qual determinadas instituições situam-se em um plano superior às demais, relacionando-se, frequentemente, através de relações verticais; ou policêntrico, em que existem múltiplas conexões entre diferentes autoridades, que se estruturam a partir da sobreposição de jurisdições, independentemente da presença de uma ordem hierárquica. Normalmente, as jurisdições referentes às instituições internacionais podem se sobrepor, é dizer, nenhuma é superior a outra, consagrando um padrão estrutural policêntrico ${ }^{19}$.

\subsection{O Acordo de Paris e a Lógica Policêntrica da Governança Internacional Climática}

Conforme especificado anteriormente, as ordens hierárquicas e policêntricas devem ser compreendidas como modelos ideias, sendo que as características de ambos estão presentes em diversos sistemas empíricos, o que determina a preferencia por visualizar elementos de um sistema é, justamente, a determinação de uma perspectiva de investigação em correspondência com a lógica imperante no âmbito de suas relações institucionais. É dizer, a

\footnotetext{
17 Daniel Bodansky, Jutta Brunnée and Lavanya Rajamani. International Climate Change Law. Oxford University Press (2017), p. 260.

18 Ernani Contipelli. Multi-level Climate Governance: Policentricity and Local Innovation. Revista Catalana de Derecho Ambiental, Vol. IX, Núm. 2: 1 - 35, 2018, p. 15

19 Daniel Bodansky, Jutta Brunnée and Lavanya Rajamani, supra nota 15, p. 261.
} 
CONTIPELLI, Ernani. Policentrismo, governança climática e constitucionalismo global. Revista Eletrônica Direito e Política, Programa de Pós-Graduação Stricto Sensu em Ciência Jurídica da UNIVALI, Itajaí, v.14, n.1, $1^{\circ}$ quadrimestre de 2019. Disponível em: www.univali.br/direitoepolitica - ISSN 1980-7791

identificação e predominância de elementos policêntricos em um sistema inclui uma tarefa de interpretação que possibilita a contextualização de sua dinâmica e o reconhecimento da lógica que sustenta as múltiplas relações entre as instituições que formam esse sistema20.

Contemporaneamente, a lógica que sustenta o modelo de governança climática foi alterada. Desde o advento do Acordo de Paris, a abordagem policêntrica passou a ser adotada como perspectiva predominante para investigação das relações institucionais relacionadas com a mudança climática, substituindo a dinâmica monocêntrica que até então prevalecia com o Protocolo de Kyoto. 0 Acordo de Paris reconhece, assim, a presença geral de politicas nacionais e de diferentes níveis de poder como fatores impulsionadores das ações climáticas, as quais permitem que os países estabeleçam suas próprias metas para minimizar as emissões de gases de efeito estufa.

Robert Falkner, ao destacar os fracassados esforços para realização de um acordo global sobre reduções obrigatórias de emissões, propõe que a nova abordagem regulatória adotada pelo Acordo de Paris conseguiu transformar as negociações internacionais de um conflito distributivo sobre metas legalmente vinculantes em um processo voluntario e "bottom-up" de mitigações, ao permitir que os países determinassem de forma independente seus próprios esforços de redução de emissão de gases de efeito estufa, removendo uma grande barreira estabelecida para o desenvolvimento das negociações climáticas pós-Kyoto ${ }^{21}$.

Nesse contexto, as Contribuições Nacionalmente Determinadas (NDCs, sigla em inglês) consistem no elemento essencial para a compreensão da lógica policêntrica incorporada ao Acordo de Paris. Elas refletem as ações que cada país promete consagrar e declaram suas aspirações e esforços de longo prazo, para

\footnotetext{
${ }^{20} \mathrm{Em}$ tais termos, pode-se assegurar que a perspectiva de investigação policentrica dos modelos de governança global possui uma significante base sólida na realidade empírica, especialmente, no âmbito da governança climática, que, ao somar os esforços de atores estatais e não-estatais para gestão da crise climática mundial, apresenta iniciativas diversificadas, multiniveladas e ascendentes, que crescem de maneira simultânea e reforçada (Andrew J. Jordan, Dave Huitema, Harro van Asselt et al. Emergence of polycentric climate governance and its future prospects. Nature Climate Change, publicação on-line 10/08/2015, DOI: 10.1038/NCLIMATE2725).

${ }^{21}$ Robert Falkner. The Paris Agreement and the New Logic of International Climate Politics. International Affairs, 92, 1107-112 (2016), p. 1124.
} 
CONTIPELLI, Ernani. Policentrismo, governança climática e constitucionalismo global. Revista Eletrônica Direito e Política, Programa de Pós-Graduação Stricto Sensu em Ciência Jurídica da UNIVALI, Itajaí, v.14, n.1, $1^{\circ}$ quadrimestre de 2019. Disponível em: www.univali.br/direitoepolitica - ISSN 1980-7791

responder às mudanças climáticas, oferecendo metas relacionadas à redução, adaptação e métodos de implementação (finanças, tecnologia, capacitação e transparência).

É certo que as condicionantes sociais e econômicas de cada pais refletem as dificuldades enfrentadas para alcançar metas consistentes de mitigação, de modo que a perspectiva policêntrica de governança contribui para o ajuste e a contextualização de politicas dentro da capacidade de uma nação para lidar com a questão climática e, simultaneamente, dar prosseguimento ao seu respectivo processo de desenvolvimento.

O processo de submissão das NDCs e a futura revisão dos mecanismos propostos pelo Acordo de Paris demonstram a presença de diversas características do policentrismo no âmbito da governança climática, especialmente, em relação à inclusão de "catalisadores de confiança", ou seja, a construção intencional da confiança entre um numero limitado de atores, em termos de estruturas relacionais, enfatizando o valor da comunicação face-a-face, bem como atuando como um elemento de prevenção no que se refere a ausência de comprometimento com a luta contra a crise climática ${ }^{22}$.

Ao analisar a lógica da cooperação climática internacional, Robert O. Keohane e David G. Victor destacaram a necessidade de inclusão de técnicas promissoras no âmbito do policentrismo, como, por exemplo, a realização de pesquisas e de ações nacionais coordenadas com a concessão de benefícios substancias às nações que implementem tais atividades. Tal perspectiva pretende sugerir mais do que um enfoque na atuação singular de uma instituição, e sim um resultado final concebido a partir da combinação de estratégias para governança de questões nacionais e locais relacionadas com a mudança climática. E afirmam que, durante anos, esses resultados complexos e descentralizados eram compreendidos como algo temido, mas a investigação contemporânea dos modelos de cooperação conclui que eles se tratam de elementos essenciais. Os Estados devem cooperar onde a cooperação é extremamente difícil ou onde a

22 Marcel J. Dorsch and Christian Flatchsland. A Polycentric Approach to Global Climate Governance. Global Environmental Politics, Vol. 17, Number 2, 45-64 (2017), p. 57. 
CONTIPELLI, Ernani. Policentrismo, governança climática e constitucionalismo global. Revista Eletrônica Direito e Política, Programa de Pós-Graduação Stricto Sensu em Ciência Jurídica da UNIVALI, Itajaí, v.14, n.1, $1^{\circ}$ quadrimestre de 2019. Disponível em: www.univali.br/direitoepolitica - ISSN 1980-7791

participação universal é desejável; e investigar experimentalmente para procurar expandir os limites da cooperação, uma vez que nenhum caminho único é susceptível de ser globalmente eficaz por si só, devendo ser realizada uma multiplicidade de ações e tentativas ${ }^{23}$.

Uma das críticas suscitadas em relação à perspectiva policêntrica de gestão da mudança climática diz respeito à fragmentação do sistema de governança e de seu potencial para gerar conflitos e replicação de esforços. Por exemplo, no caso de politicas locais que, em determinados momentos, podem entrar em conflitos com demais relações intergovernamentais, como as estratégias de desenvolvimento nacional ou regional.

Para amenizar os efeitos de tal handicap, a institucionalização compartilhada de um conjunto abrangente de princípios e de regras pode estabelecer um caminho para orientar as unidades de um sistema policêntrico em favor da coordenação, incrementando o potencial de efetividade de suas respectivas atuações e, ao mesmo tempo, evitando contradições e possíveis conflitos. Em tal contexto, as instituições "top down" são fundamentais para formação e manutenção de um sistema de governança policêntrica, na medida em que facilitam a coordenação de atividades entre seus múltiplos atores participantes, resolvem as disputas entre unidades situadas em nível de governança inferiores e permitem 0 intercambio de dados sobre iniciativas de sucesso e que podem ser transferidas de uma localidade para outra24.

Portanto, um conjunto abrangente de princípios e regras geram as condições adequadas para promoção de um modelo de auto-organização institucional em uma perspectiva policêntrica, ao assegurar a coordenação de todo o sistema e garantir maior efetividade na execução de ações, conciliando o desempenho dos diferentes níveis de governança. Essas regras também potencializam um maior

\footnotetext{
23 Robert O. Keohane and David G. Victor. Cooperation and Discord in Global Climate Policy. Nature Climate Change 6, (2016), p. 11.

24 Thomas Bauwens. Polycentric Governance Approaches for a Low-Carbon Transition: The Roles of Community-Based Energy Initiatives in Enhancing the Resilience of Future Energy Systems. In Labanca, N. (ed), Complex Systems and Social Practices in Energy Transitions: Framing Energy Sustainability in the Time of Renewables, pp. 119-145, London: Springer, 2017, p. 126.
} 
CONTIPELLI, Ernani. Policentrismo, governança climática e constitucionalismo global. Revista Eletrônica Direito e Política, Programa de Pós-Graduação Stricto Sensu em Ciência Jurídica da UNIVALI, Itajaí, v.14, n.1, $1^{\circ}$ quadrimestre de 2019. Disponível em: www.univali.br/direitoepolitica - ISSN 1980-7791

intercambio de informações que facilitam a resolução de conflitos e fomentam negociações entre as unidades de governo em diferentes níveis de poder.

Diante de tais considerações, a Convenção-Quadro das Nações Unidas sobre Mudanças Climáticas (UNFCCC, sigla em inglês) possui um papel fundamental no âmbito da governança climática, ao estabelecer um "corpo de regras abrangentes" que vinculam outras regulamentações, normas, valores e politicas relacionadas à mudança climática, para assegurar que objetivos mais amplos sejam constantemente alcançados, resolver conflitos entre diferentes instituições e balancear as relações de poder entre os atores envolvidos.

Ao atuar como um corpo de regras abrangentes, a UNFCCC incrementa as vantagens da perspectiva policêntrica de governança multinível, maximizando o potencial de ações coordenadas e cooperativas entre distintas instituições para enfrentar a crise climática, especialmente, no âmbito local, que possui o papel de um laboratório para experimentações destinado a produzir resultados inovadores que podem servir de modelo de implementação em outras jurisdições. Logicamente, esse potencial transformador deve ser vinculado e compatibilizado às politicas climáticas nacionais e globais, particularmente dentro dos limites estabelecidos pelas regras gerais.

A perspectiva policêntrica de governança climática destaca, assim, a participação de diferentes níveis de poder, especialmente no âmbito local, justificando seu envolvimento ativo na produção de estratégias minimizadoras e adaptativas para os demais níveis de governança (regional, nacional e transnacional). O crescente reconhecimento da função crucial das iniciativas locais em lidar com as questões climáticas tornou-se uma realidade e constitui uma parte da dinâmica e da lógica presentes no sistema de governança climática, o qual busca o constante equilíbrio entre metas globais e expectativas internas de ação, o que conduz a refletir sobre propostas teóricas que melhor possibilitem a compreensão do conceito de "princípios e regras abrangentes" no policentrismo, auxiliando na coordenação da atuação entre distintos âmbitos de ação, como o modelo teórico proposto pelo Constitucionalismo Climático Global. 
CONTIPELLI, Ernani. Policentrismo, governança climática e constitucionalismo global. Revista Eletrônica Direito e Política, Programa de Pós-Graduação Stricto Sensu em Ciência Jurídica da UNIVALI, Itajaí, v.14, n.1, $1^{\circ}$ quadrimestre de 2019. Disponível em: www.univali.br/direitoepolitica - ISSN 1980-7791

\section{CONSTITUCIONALISMO CLIMÁTICO GLOBAL}

Como um modelo ideal de governança, os sistemas policêntricos também envolvem em sua disposição a presença de instituições top-down, as quais são vitais para sua formação e manutenção, na medida em que, conforme afirmado anteriormente, facilitam a coordenação de atividades entre múltiplos participantes, resolvem as disputas entre os diferentes níveis de governança e permitem a troca de informações, especialmente, em relação às estratégias bem sucedidas.

Desse modo, o policentrismo pode se valer da teoria do constitucionalismo global ${ }^{25}$ para adquirir a necessária coordenação entre as distintas unidades de governança pertencentes a um sistema, como forma de estimular a multiplicação de iniciativas institucionais e combater os efeitos adversos da mudança climática.

De acordo com Anne Peters e Klaus Armigeon, o conceito de constitucionalismo global tem um papel importante como agenda acadêmica e politica que identifica e advoga para aplicação dos princípios constitucionalistas na esfera legal internacional para incrementar sua efetividade ${ }^{26}$, estimulando a inserção de elementos descritivos e prescritivos no sistema de governança global, para determinar múltiplos argumentos que orientam o desenvolvimento das relações institucionais em direção a uma especifica e convergente promoção de interesses públicos coletivos.

\footnotetext{
25 Os efeitos institucionais do processo de globalização demonstram uma decadência não apenas dos Estados-nação, mas também das estruturas constitucionais e de seus princípios, os quais se tornaram disfuncionais e vazios (Anne Peters, The Constitutionalization of State Constitutions. In J. Nijman and A. Nollkaemper (Eds.) New Perspectives on the Divide Between National and International Law. Oxford: Oxford University Press, 2007, pp. 251-308). Como consequência, o objetivo atual das estruturas constitucionais consiste em sobreviver na fragmentada e globalizada arena das negociações internacionais. Portanto, a ideia de constitucionalismo global aparece como uma compreensiva revisão e releitura do degenerado conceito contemporâneo de constitucionalismo, que busca estabelecer uma compensação pela transferência de funções dos Estados-nação para o plano internacional e uma adaptação dos valores e princípios essenciais oferecidos pela historia do constitucionalismo em conjunto com as necessidades globais contemporâneas.
}

26 Anne Peters e Klaus Armigeon Global Constitutionalism from an Interdisciplinary Perspective. Indiana Journal of Global Legal Studies, vol. 16, n. 02, Special Issue, pp. 385-395, 2009, p. 389. 
CONTIPELLI, Ernani. Policentrismo, governança climática e constitucionalismo global. Revista Eletrônica Direito e Política, Programa de Pós-Graduação Stricto Sensu em Ciência Jurídica da UNIVALI, Itajaí, v.14, n.1, $1^{\circ}$ quadrimestre de 2019. Disponível em: www.univali.br/direitoepolitica - ISSN 1980-7791

Em tais termos, a questão que surge refere-se a como transplantar para o nível internacional uma especifica concepção de constitucionalismo que não apenas consista na sua recolocação, mas que o contextualize, estabelecendo um marco jurídico de valores e de princípios em linha com as peculiaridades das relações internacionais contemporâneas e de suas forças atuantes, para efetivamente guiar o processo de tomada de decisões institucionais no multifacetário sistema de governança global ${ }^{27}$.

Considerando as características do policentrismo e sua proposta de maximização do potencial inovador dos sistemas de governança, o constitucionalismo, situado no contexto da sociedade globalizada, em que os grandes problemas enfrentados pela humanidade adquirem dimensões planetárias, pode ser compreendido a partir do conceito de "micro-constituições-globais" relacionadas com uma determinada área de interesse dos diversos sistemas de governança global.

Assim, a perspectiva policentrica constitucional pretende identificar bens coletivos distintos dentro de cada sistema social, os quais são objeto de interesse de regulamentações significantes fora das fronteiras dos Estados-nação, para, a partir de tal concepção e valoração, desenvolver modelos constitucionais setoriais sustentados por um conjunto de princípios e regras abrangentes, fornecidos por tratados internacionais que reconhecem os valores e objetivos centrais da herança do constitucionalismo.

Trata-se de uma ferramenta analítica que visa promover uma convergência sistemática de normas e de politicas públicas, enfatizando ações coletivas e estimulando a aplicação da narrativa do constitucionalismo global, por intermédio de um processo bottom-up focalizado na flexibilidade das condições estruturais de experimentação e adaptação à aprendizagem ajustado à realidade policêntrica dos modelos institucionais de governança global.

27 Ernani Contipelli. Constitucionalismo Climático Global. Revista Justiça do Direito, v. 32, n. 02, pp. 278-300, 2018, p. 284. 
CONTIPELLI, Ernani. Policentrismo, governança climática e constitucionalismo global. Revista Eletrônica Direito e Política, Programa de Pós-Graduação Stricto Sensu em Ciência Jurídica da UNIVALI, Itajaí, v.14, n.1, $1^{\circ}$ quadrimestre de 2019. Disponível em: www.univali.br/direitoepolitica - ISSN 1980-7791

\subsection{Policentrismo e "Micro-Constitucionalismo Climático Global"}

Ao acompanhar o dinamismo da sociedade globalizada, o constitucionalismo deve ser compreendido como um trabalho constante que necessita estruturar sua própria narrativa. Em tal sentido, Daniel Bodansky destaca os aspectos constitutivos de muitos tratados internacionais, especialmente, relacionados com temas ambientais, os quais possuem uma verdadeira dimensão constitucional em sentido sutil, ao apresentarem flexibilidade e dinamismo para estabelecer sistemas de governança destinados a regular questões especificas como o caso da mudança climática. Assim, Bodansky pondera que "cada tratado internacional realiza funções constitutivas básicas a partir do estabelecimento de instituições, da especificação de regras que guiam e restringem as mencionadas instituições e aumentando essas regras através de procedimentos de reforma" 28 .

Importante esclarecer que o conceito de constituição sutil é focada em suas características procedimentais, que, conforme Alec Stone Sweet, pode ser definida como um corpo de meta-normas, ou seja, conjunto de regras legais e de princípios de alta hierarquia, que especificam como as demais normas de menor hierarquia devem ser produzidas, aplicadas, executadas e interpretadas ${ }^{29}$. Desta feita, é possível constatar que alguns regimes jurídicos internacionais apresentam essas características, fazendo com que eles possuam um significante sentido constitucional, ao conformar uma ordem constitucional global sobre temas específicos.

O processo de construção de tais ordens constitucionais globais, que podemos denominar "micro-constituições-globais", reconhecem a existência de elementos constitutivos e regulatórios estipulados por diferentes documentos que preveem a estrutura básica de um sistema e sua dinâmica, destacando as sobreposições jurisdicionais internas e externas, assim como a convergência de ações e o estabelecimento de padrões de comportamento social.

\footnotetext{
28 Daniel Bodansky. Is There an International Environmental Constitution?, p. 569. Indiana Journal of Global Legal Studies, vol. 16, pp. 565-584, 2009, p. 574.

${ }^{29}$ Alec Stone Sweet. Constitutionalism, Legal Pluralism, and International Regimes. Indiana Journal of Global Legal Studies, vol 16, 2009, p. 626.
} 
CONTIPELLI, Ernani. Policentrismo, governança climática e constitucionalismo global. Revista Eletrônica Direito e Política, Programa de Pós-Graduação Stricto Sensu em Ciência Jurídica da UNIVALI, Itajaí, v.14, n.1, $1^{\circ}$ quadrimestre de 2019. Disponível em: www.univali.br/direitoepolitica - ISSN 1980-7791

Em outras palavras, as "micro-constituições-globais" fazem parte de um abrangente conceito de constitucionalismo global que inspira seu processo de construção e objetiva atribuir-lhe uma conteúdo de coercibilidade expressado, particularmente, pela multiplicação de ações de conteúdo policêntrico em distintas escalas de governança.

Daniel Bodansky explica que alguns instrumentos constitutivos representam a "ponta do iceberg normativo dentro dos regimes que eles estabelecem", atribuindo flexibilidade e dinâmica aos mecanismos de governança para criação de normas relacionadas a uma determinada área. Nessa ordem de ideias, é possível distinguir entre elementos constitutivos e não-constitutivos, possibilitando uma melhor compreensão da estrutura e do desenvolvimento de um sistema normativo internacional relacionado com o meio ambiente ${ }^{30}$.

Por um lado, os elementos constitutivos estipulados por um tratado ou por um conjunto de tratados confere a estrutura básica de um regime jurídico internacional ambiental, estabelecendo suas instituições básicas e seu processo de decisão, da mesma forma que uma Constituição, sendo inclusive mais difíceis de serem modificados. Por outro lado, os elementos regulatórios são estabelecidos em diferentes documentos como protocolos ou anexos e são mais flexíveis, ou seja, passiveis de alterações.

No caso especifico da governança climática, o micro-constitucionalismoclimático-global pode ser considerado como parte integrante do regime jurídico internacional ambiental, o qual é composto por uma serie de micro-constituiçõesglobais, estabelecidas de acordo com a presença de elementos constitutivos e regulatórios que refletem a herança do constitucionalismo.

Resta compreendido que, com a abordagem policêntrica, o constitucionalismo climático global, reconhecidamente um conjunto de valores, princípios e regras compartilhados, abre caminho para que as unidades integrantes de um modelo de governança se auto-organizem, coordenando efetivamente suas atuações no

30 Daniel Bodansky, supra nota 26, p. 575. 
CONTIPELLI, Ernani. Policentrismo, governança climática e constitucionalismo global. Revista Eletrônica Direito e Política, Programa de Pós-Graduação Stricto Sensu em Ciência Jurídica da UNIVALI, Itajaí, v.14, n.1, $1^{\circ}$ quadrimestre de 2019. Disponível em: www.univali.br/direitoepolitica - ISSN 1980-7791

nível social, para evitar contradições que prejudicam a efetividade da convergências de esforços entre múltiplos atores.

Em particular, a construção da narrativa do micro-constitucionalismo-climáticoglobal, o qual se encontra evidentemente relacionado a um regime especializado, proporciona um arcabouço legal destinado a garantir a coordenação de distintas atuações e a resolução de possíveis disputas no âmbito da governança climática, abordando esforços multiníveis em direção a estratégias comuns de combate a tal crise de dimensões planetárias.

\section{CONSIDERAÇÕES FINAIS}

Os sistemas policêntricos são caracterizados por múltiplos centros de autoridade decisória com jurisdições sobrepostas que não apresentam um relacionamento hierárquico; em vez disso, eles competem e, ao mesmo tempo, cooperam uns com os outros. Suas interações são desenvolvidas através de um processo de ajustamento mútuo de colaboração espontânea e de aprendizado continuo, que implicam na estipulação de padrões de comportamento regularizados dentro uma ordem social abrangente. Além disso, a perspectiva de governança policêntrica estimula a pesquisa e a experimentação, buscando como resultado projetos inovadores que se tornam modelos para outras jurisdições em um mesmo ou em diferentes níveis.

Logicamente, a perspectiva policêntrica de investigação de modelos de governança é passível de criticas, particularmente, em relação à probabilidade de fragmentação analítica de um determinado sistema e a ausência de coordenação entre suas diferentes unidades constitutivas. Em tal momento, constata-se a necessária presença de um corpo abrangente de princípios e regras para funcionar como um elemento de convergência das múltiplas ações desempenhadas por um dado modelo de governança, maximizando o potencial de suas diferentes instituições, especialmente, no gerenciamento de problemas globais. 
CONTIPELLI, Ernani. Policentrismo, governança climática e constitucionalismo global. Revista Eletrônica Direito e Política, Programa de Pós-Graduação Stricto Sensu em Ciência Jurídica da UNIVALI, Itajaí, v.14, n.1, $1^{\circ}$ quadrimestre de 2019. Disponível em: www.univali.br/direitoepolitica - ISSN 1980-7791

Tais princípios e regras referentes à abordagem policêntrica derivam de um regime internacional especializado que influencia as unidades de governança em diferentes escalas de poder e seus respectivos interesses, os quais passam a atuar como multiplicadores de compromissos direcionados à gestão de problemas globais. Ademais, em um mundo globalizado, os esforços para construir dentro de uma abordagem policêntrica uma narrativa baseada na teoria do constitucionalismo global centram-se na capacidade de preservação do patrimônio constitucional e de sua atual agenda social global, para contribuir com elementos substantivos que resgatem a figura do Estado-nação em seu papel de apoio aos diversos níveis de governança existentes no sistema climático.

Portanto, a aplicação da abordagem policêntrica ao constitucionalismo global voltada à governança multinível climática oferece uma oportunidade de inovação a todo sistema internacional climático, gerando um esquema compreensivo de princípios e regras que orientam a coordenação de iniciativas entre diversos níveis de autoridade em direção a um dinâmico e progressivo modelo de governança, que pretende enfatizar esforços coletivos destinados a garantir a cooperação entre os diferentes atores envolvidos no combate da crise climática.

\section{REFERÊNCIAS DAS FONTS CITADAS}

BAUWENS, Thomas (2017). Polycentric Governance Approaches for a LowCarbon Transition: The Roles of Community-Based Energy Initiatives in Enhancing the Resilience of Future Energy Systems. In Labanca, N. (ed), Complex Systems and Social Practices in Energy Transitions: Framing Energy Sustainability in the Time of Renewables, pp. 119-145, London: Springer.

BODANSKY, Daniel (2009). Is There an International Environmental Constitution? Indiana Journal of Global Legal Studies, vol. 16, pp. 565-584. ., Jutta Brunnée and Lavanya Rajamani (2017). International Climate Change Law. Oxford University Press. 
CONTIPELLI, Ernani. Policentrismo, governança climática e constitucionalismo global. Revista Eletrônica Direito e Política, Programa de Pós-Graduação Stricto Sensu em Ciência Jurídica da UNIVALI, Itajaí, v.14, n.1, $1^{\circ}$ quadrimestre de 2019. Disponível em: www.univali.br/direitoepolitica - ISSN 1980-7791

COLE, Daniel H. (2011). From Global to Polycentric Climate Governance. Climate Law 2, 395-413.

- (2015). Advantages of a Polycentric Approach to Climate Change Policy. Nature Climate Change, vol. 05.

CONTIPELLI, Ernani (2018). Multi-level Climate Governance: Policentricity and Local Innovation. Revista Catalana de Derecho Ambiental, Vol. IX, Núm. 2: 1 35.

- (2018) Constitucionalismo Climático Global. Revista Justiça do Direito, v. 32, n. 02, pp. 278-300.

. (2017) Trump's Doctrine and Climate Change: New Challenges for Global Governance. IndraStra Global, v. 3, n. 5, 2017, p. 3-68.

DORSCH, Marcel J. and FLATCHSLAND, Christian (2017). A Polycentric Approach to Global Climate Governance. Global Environmental Politics, Vol. 17, Number 2, 45-64.

FALKNER, Robert (2016). The Paris Agreement and the New Logic of International Climate Politics. International Affairs, 92, 1107-112.

JORDAN, Andrew J., HUITEMA, Dave, VAN ASSELT, Harro et al. Emergence of Polycentric Climate Governance and its Future Prospects. Nature Climate Change, publicação on-line 10/08/2015, DOI: 10.1038/NCLIMATE2725

KEOHANE, Robert O. and VICTOR, David G. (2016). Cooperation and Discord in Global Climate Policy. Nature Climate Change 6.

OSTROM, Elinor (2010). Polycentric Systems for Coping with Collective Action and Global Environmental Change, Global Environmental Change 20, 550-557. . (2010) A Multi-Scale Approach to Coping with Climate Change and Other Collective Action Problems. Solutions 1 (2): 27-36. 
CONTIPELLI, Ernani. Policentrismo, governança climática e constitucionalismo global. Revista Eletrônica Direito e Política, Programa de Pós-Graduação Stricto Sensu em Ciência Jurídica da UNIVALI, Itajaí, v.14, n.1, $1^{\circ}$ quadrimestre de 2019. Disponível em: www.univali.br/direitoepolitica - ISSN 1980-7791

. (2009) A Polycentric Approach for Coping with Climate Change. Policy Research Working Paper 5095, World Bank.

., WALKER, James M., GARDNER, Roy and HERR, Andrew (2000). Collective Choice in the Commons: Experimental Results on Proposed Allocation Rules and Votes. The Economic Journal, 110, 212-234.

OSTROM, Vicent, TIEBOUT, Charles M. and WARREN, Robert (1961). The Organization of Government in Metropolitan Areas: A Theoretical Inquiry. American Political Science Review 55 (4), 831-842. - (1999) Polycentricity - Part I. In Polycentricity and Local Public Economics. Ed. Michel Mc Ginis, 52-74. Ann Arbor: University of Michigan Press.

PETERS, A. (2007) The Constitutionalization of State Constitutions. In J. Nijman and A. Nollkaemper (Eds.) New Perspectives on the Divide Between National and International Law. Oxford: Oxford University Press, pp. 251-308

. and ARMIGEON, K. (2009) Global Constitutionalism from an Interdisciplinary Perspective. Indiana Journal of Global Legal Studies, vol. 16, n. 02, Special Issue, pp. 385-395.

STONE SWEET, Alec (2009). Constitutionalism, Legal Pluralism, and International Regimes. Indiana Journal of Global Legal Studies, vol 16.

SOVACOOL, Benjamin K. (2011). An International Comparison of Four Polycentric Approaches to Climate and Energy Governance. Energy Policy, 39, 3832-3844.

RECEBIDO EM: 20/11/2018

APROVADO EM: 01/03/2019 